\title{
THE PREVALENCE OF DENTAL CARIES AMONG YOUNG ADULTS IN CAIRO- EGYPT. A STATISTICAL STUDY
}

\author{
Hala Fares*
}

\begin{abstract}
To date, it is inevitable; according to the available epidemiological data; that the prevalence of dental caries is rapidly increasing. In this cross- sectional study, a survey was conducted on 3778 secondary school students aged 15-18 years old. The overall prevalence of dental caries was determined (53.8\%); and a comparison was set between male and female candidates regarding the prevalence of caries where no statistical significance was reported.
\end{abstract}

KEYWORDS: prevalence of dental caries, young adults, gender difference.

\section{INTRODUCTION}

The global increase in dental caries prevalence affects children as well as adults, primary as well as permanent teeth and coronal as well as root surfaces $^{(1)}$. This increase in dental caries signals a pending public health crisis and could produce a serious negative impact upon the future of oral health (and systemic health) of the global community, as well as a strain on the dental profession along with a major increase in the cost of dental services ${ }^{(1)}$.

The large movements of rural people to urban centers in search of new manufacturing jobs had in impact on the prevalence of caries. These populations have left the rural life for urban labor with the attending negative changes in diet life style and health ${ }^{(2)}$. According to the United States
Surgeons General's report ${ }^{(3)}$, dental caries is stated to be the most common chronic disease and is five times more common than asthma and seven times more common than hay fever.

Dental caries remains a major dental public health problem in disadvantaged communities in both developing and industrialized countries ${ }^{(4)}$ Concern has been expressed that caries is increasing in many of the developing countries ${ }^{(5)}$ so, evidence about caries trends needs to be systematically examined. This may be done with a systematic literature review which is a corner stone of evidence-based medicine and is suitable for examining reported disease trends ${ }^{(6)}$. There is a clear need for caries surveillance through regular field survey in selected parts of a country ${ }^{(7)}$. The control of dental caries is a continuing problem and it is easier to manage

* Lecturer, Department of Operative and Cosmetic Dentistry, Faculty of Oral and Dental Medicine, Misr University for Science and Technology. Egypt. 
if groups of populations with greatest needs are identified. High risk groups should be identified and categorized in order to implement preventive and restorative procedure in the targeted groups ${ }^{(8,9)}$. In the United States, over $78 \%$ of 17 years old young adults have, at least one cavity or restoration ${ }^{(10)}$. In Brazil, an epidemiological survey ${ }^{(11)}$ was conducted in Sau Paulo, Brazil among 1.151 randomly selected school candidates and the prevalence of dental caries in the permanent dentition was reported to be $53.6 \%$. In Peru, a study ${ }^{(12)}$ reported that clinical examination results showed the prevalence of dental caries in the permanent dentition to be $78.5 \%$. In the United Kingdom, the 2003 survey of government maintained and independent schools showed a caries prevalence $55 \%$ of 15 years old young adults. In India, a very extensive and comprehensive national health survey ${ }^{(13)}$ was conducted in 2004 throughout the entire country in order to ascertain the oral health status and prevalence of dental caries in different age groups. The study showed a caries prevalence of $63.1 \%$ in young adults.

In November 2006, dental authorities from across the world gathered in Geneva, Switzerland and Ferney- Voltaire, France under auspices of federation dentaire international (FDI), the world health organization (WHO) and the International Association for Dental Research (IADR) to discuss common issues related to global oral health ${ }^{(14)}$. Eighty experts from thirty countries expressed their deep concern about growing disparities in dental health and the lack of progress in tackling the worldwide burden of dental caries, particularly in disadvantaged populations ${ }^{(14)}$. A guest editorial ${ }^{(15)}$, in the October, 2007 issue of the journal of dental research in entitled : a global theme-poverty and human development reported that dental caries still affected most adults and children worldwide and that its prevalence in resource poor nations appeared to be increasing. An article ${ }^{(16)}$ in the November, 2007 issue of the journal of American dental association health, oral health and poverty reported that caries levels in developing countries had been increasing constantly. A 2006 epidemiological survey ${ }^{(17)}$ of the incidence of stomatological disease was conducted among 1.030 Russian military personal. Within the group, a very high level of oral disease was detected. It was further reported that $100 \%$ of the population had carious lesion. In 1993, in the preface to the proceedings from a conference on cariology, in a text book entitled Cariology for the Nineties ${ }^{(18)}$, it was reported that caries continued to be a public health problem worldwide and that the enigma of dental caries was worthy of the attention of the finest scientific mines and the application of the most sophisticated techniques from epidemiology to molecular biology.

Caries and its complications affect the quality of life, both physically and physiologically. Scientific research continues to make progress in identification of best practices for diagnosis, treating and preventing dental caries ${ }^{(1)}$. The age group used in this study was seldom targeted in other studies which provides advantages and uniqueness in this study.

\section{METHODS AND MATERIALS}

\section{Study design: Cross-sectional study}

\section{Sampling:}

Cluster sampling technique (Random sampling) was utilized to select participants in the present study. The Directorate of Education in Cairo has 16 Administrations classified on geographic basis .

Eight administrations were randomly selected and then two private schools from each administration were selected giving rise to 16 schools. Within each school, 6 secondary stage classes were randomly selected $\left(2\right.$ classes from $1^{\text {st }}$ secondary year, 2 classes from $2^{\text {nd }}$ secondary year and 2 classes from $3^{\text {rd }}$ secondary year). All students who follow the inclusion criteria within each class were examined. 
Inclusion criteria:

1. Egyptian nationality.

2. Both genders.

3. Age range (15-18 years)

4. Free of systemic disease or congenital anomalies.

\section{Exclusion criteria:}

1. Orthodontically treated students.

The study was conducted on 3778 students.

\section{Statistical Analysis}

Qualitative data were presented as frequencies (n) and percentages. Chi-square $\left(x^{2}\right)$ test was used for comparisons between caries prevalence in males and females.

Quantitative data were presented as mean, median, standard deviation (SD), and range (Minimum - Maximum) values. Data were explored for normality by checking the data distribution and using Kolmogorov-Smirnov and Shapiro-Wilk tests. DMF data showed non-parametric distribution.

Mann-Whitney $U$ test was used to compare between DMF findings in males and females.

The significance level was set at $\mathrm{P} \leq 0.05$. Statistical analysis was performed with IBM $^{\circledR}$ SPSS $^{\circledR}$ Statistics Version 20 for Windows.

\section{RESULTS}

The present study was conducted on 3778 students; 1715 males (45.4\%) and 2063 females $(54.6 \%)$.

Caries prevalence was $53.8 \%$ in the whole sample. Caries prevalence in males was $55.2 \%$ and in females it was $52.5 \%$. There was no statistically significant difference between caries prevalence in

(B) IBM Corporation, NY, USA.

(R) SPSS, Inc., an IBM Company. males and females $(P$-value $=0.101)$.

The mean and standard deviation values of DMF in the whole sample were $2.03 \pm 1.27$ with a median of 1 , minimum of 0 and a maximum of 7 .

The mean and standard deviation values of DMF in males were $3.11 \pm 1.70$ with a median of 2 , minimum of 0 and a maximum of 7 .

The mean and standard deviation values of DMF in females were $2.95 \pm 1.64$ with a median of 2 , minimum of 0 and a maximum of 7 .

There was no statistically significant difference between DMF scores in males and females ( $P$-value $=0.775)$.

TABLE (1) Frequency, percentages and results of chi-square test for comparisons between caries prevalence in males and females

\begin{tabular}{|c|c|c|c|c|c|}
\hline & \multicolumn{2}{|c|}{$\begin{array}{c}\text { Males } \\
(\mathrm{n}=1715)\end{array}$} & \multicolumn{2}{c|}{$\begin{array}{c}\text { Females } \\
(\mathrm{n}=2063)\end{array}$} & \multirow{2}{*}{ P-value } \\
\cline { 2 - 5 } & $\mathrm{n}$ & $\%$ & $\mathrm{n}$ & $\%$ & \\
\hline Caries & 947 & 55.2 & 1084 & 52.5 & \multirow{2}{*}{0.101} \\
\hline Caries-free & 768 & 44.8 & 979 & 47.5 & \\
\hline
\end{tabular}

*: Significant at $P \leq 0.05$

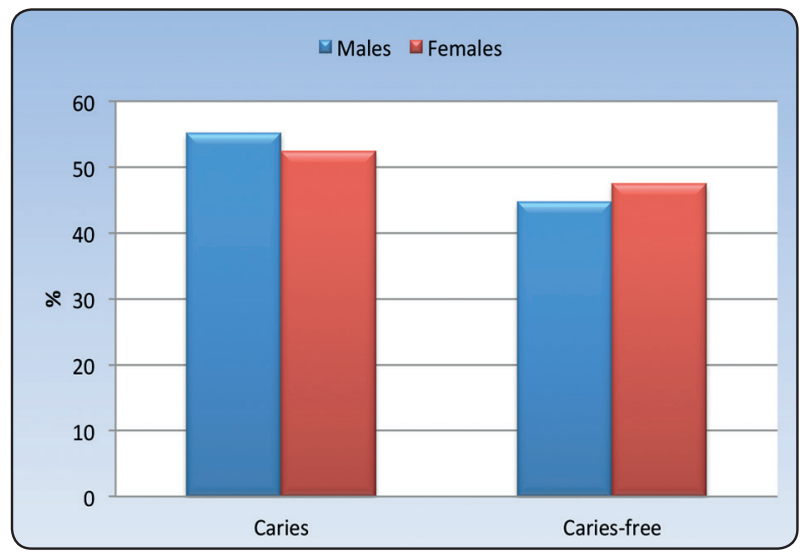

Fig. (1): Bar chart representing prevalence of caries in males and females 
TABLE (2) Descriptive statistics and results of Mann-Whitney $\mathrm{U}$ test for comparison between DMF scores in males and females

\begin{tabular}{|c|c|c|c|}
\hline & $\begin{array}{c}\text { Males } \\
(\mathrm{n}=1715)\end{array}$ & $\begin{array}{c}\text { Females } \\
(\mathrm{n}=2063)\end{array}$ & $P$-value \\
\cline { 1 - 3 } Mean (SD) & $3.11(1.70)$ & $2.95(1.64)$ & \multirow{2}{*}{0.775} \\
\cline { 1 - 3 } Median (Range) & $2(0-7)$ & $2(0-5)$ & \\
\hline
\end{tabular}

*: Significant at $P \leq 0.05$

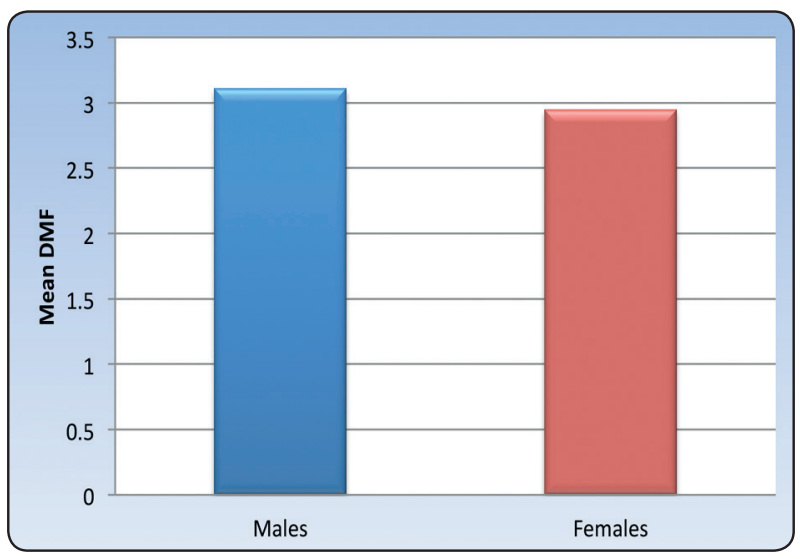

Fig. (2) Bar chart representing mean DMF scores in males and females

\section{DISCUSSION}

Although some studies claim that dental caries has been declining globally in the general population $^{(19,20)}$; yet other studies may be as equal, regard dental caries prevalence as an emerging crisis ${ }^{(1-18)}$. Despite the fact that there has been a great progression in diagnostic methods and devices; restorative materials, strategiesthat emphasize disease prevention and conservation of tooth structure, the problem still remains. Certain cateogories still suffer, examples include poor people, families without dental insurance, families under insurance programs without effective dental coverage and a large percentage people in developing countries. In this study it was though that assessment of dental caries prevalence in Cairo-
Egypt would be of interest providing useful clues to the general overall prevalence in dental caries in Egypt. The survey of this study was targeted at secondary schools' students (young adults) aged 15-18; because of their easy accessibility. A cross sectional study was conducted using cluster sampling techniques. The study was conducted on 3778 students in order to provide the reliability to the studies. Statistical tests for analysis were performed as described in the methodology. Results showed an overall prevalence of dental caries as $(53.8 \%)$. Also there was no statistically significant difference between caries prevalence in males and females. This study tackled an age group that was seldom tackled by previous studies in addition to using a comparatively large sample size which provided more reliability.

\section{CONCLUSION}

It is not sufficient to rely on the progress in diagnostic methods and recent preventive and restorative procedures to fight dental caries progression.

High risk groups of population should be appropriately identified and categorized in order to effectively implement preventive and restorative procedures.

\section{ACKNOWLEDGMENT}

Thanks to all resident doctors who participated in the survey of this study.

\section{REFERENCES}

1. Bagramain R, Godoy $\mathrm{F}$ and Volpe $\mathrm{A}$. the global increase in dental caries. A pending public health crisis. Am J Dent 2009; 22: 3-8.

2. Marthaler, TM. Changes in dental caries 1953-2003. Caries Res 2004; 38: 173-181.

3. United States Department of health and Human Services (USDHHS). Oral Health in America: A Report of the surgeon General. National Institute of Health, 2000. 
4. United States Department of health and Human Services (USDHHS). Nationalcall to Action to Promote Oral Health. Nationale Institute of Health, 2003.

5. Petersson HG, Bratthall D. The caries decline: a review of reviews. Eur J Oral Sci 1996; 104: 436- 443.

6. Petticrew M. Systematic reviews from astronomy to zoology: myths and misconceptions. BMJ 2001; 322: 98-101.

7. Cleaton- Jones PE, Williams SDL, Fatti LP. Surveillance of primary dentition caries in Germiston, South Africa, 19811997. Community Dent Oral Epidemiol 2000; 24: 267-273.

8. Petersson HG, Bratthall D. The caries among urban school children of Madagascar. J Comm Dent Oral Epi 1988; 16: 163-166.

9. Gupta AK, Tewari A, Chawla HS. Assessment of treatment needs of dental caries and gingival disease of South Indian population and correlation with specific risk factors. Thesis submitted in partial fulfillment of degree of M. D. S. Punjab University: Chandigarh; 1987.

10. Dye BA, Tan S, Smith V, Lewis BG, Barker LK, ThorntonEvans G, Eke PI, Beltra Aguilar ED, Horowita AM, Li CH. Trends in oral health status: United States 1988-1994 and 1999-2004. Vital Health Stat 11 2007; 248:1-92

11. Gomes PR, Costa SC, Cypriano S, Rosaro de Sousa ML. dental caries in Paulina, Sao Paulo, Brazil and World Health Organization goals for 2000 and 2010. CadSaudepublica 2004; 20:866-870.
12. United Kingdom National techniqual reports childern's Dental Health in UK, national statistics, 2003.

13. National oral health survey and fluoride mapping and epidemiological study of oral health problems and estimation of fluoride levels in drinking water. Dental council of India, New delhi, 2004.

14. Federation dentaire international (FDI), world health organization (WHO), international association for dental research (IADR) joined statement from the European dental caries conference, 2006.

15. Greenspan GS, Greenspan D. Global theme-poverty and human development. J Dent Res 2007; 86: 917-918.

16. Sgan-Cohen HD, Mann J. Health, oral health and poverty. J Am Dent Assoc. 2007; 158:1437-1442.

17. Prokhvatilov GI, Shelepov AL, Cherny SH VF Greboev GA, Nikolaiev VA. The incidence of stomatological disease among Russian military personal: the epidemiological investigation. Venno-MedtsinskiiZhurnd 2006;12: 17-21.

18. Bown WH, Tabak LA, Cariology for the nineties. Rochester University Press; Rochester, 1993.

19. First International Conference on the Declining Caries. J Dent Res 1982; 61 (SpIss).

20. Second International Conference on the Declining Caries. J Dent Res 1994; 44 (SpIss). 